\title{
COLORECTAL CANCER AND ITS RISK FACTORS AMONG PATIENTS ATTENDING A TERTIARY CARE HOSPITAL IN SOUTHERN KARNATAKA, INDIA
}

\author{
RASHMI R AITHAL ${ }^{1}$, RANJITHA S SHETTY ${ }^{2 *}$, BINU VS ${ }^{3}$, SNEHA DEEPAK MALLYA², RAJGOPAL SHENOY K ${ }^{4}$, \\ SUMA NAIR ${ }^{2}$
}

${ }^{1}$ Department of Anesthesia, Bangalore Medical College and Research Institute, Bengaluru, Karnataka, India. ${ }^{2}$ Department of Community Medicine, Kasturba Medical College, Manipal University, Manipal, Karnataka, India. ${ }^{3}$ Department of Statistics, Manipal University, Manipal, Karnataka, India. ${ }^{4}$ Department of Surgery, Kasturba Medical College, Manipal University, Manipal, Karnataka, India.

Email: ranjitha.shetty@manipal.edu

Received: 16 November 2016, Revised and Accepted: 28 January 2017

ABSTRACT

Objective: The objective of this study is to determine the association between certain sociodemographic and lifestyle factors with colorectal cancer.

Methods: This case-control study was conducted using a pre-designed questionnaire among 100 incident colorectal cancer patients and 200 unmatched controls attending a Tertiary Care Hospital in Southern Karnataka. Cases and the controls were interviewed, and details regarding their sociodemographic factors were collected. Information on lifestyle factors such as dietary habits, physical activity levels, and substance use were documented. They were also assessed for the presence of existing comorbidities and family history of colorectal and other cancers. Multivariable logistic regression was performed to determine the association between various risk factors and colorectal cancer.

Results: In the present hospital-based study, mean age of the participants was $<55$ years. About $63 \%$ of the cases and $54.5 \%$ of the controls were males. On multivariable analysis, age $\geq 50$ years (odds ratio $[\mathrm{OR}]=1.87 ; 95 \%$ confidence interval $[\mathrm{CI}]=1.02-3.45)$, low physical activity $(\mathrm{OR}=5.66 ; 95 \%$ $\mathrm{CI}=3.10-10.34)$ and low frequency of fruits consumption $(\mathrm{OR}=4.10 ; 95 \% \mathrm{CI}=2.21-7.50)$, and hypertension $(\mathrm{OR}=4.65 ; 95 \% \mathrm{CI}=1.32-16.44)$ showed a positive association with colorectal cancer.

Conclusion: Promoting healthy dietary practices and physical activity among the middle-aged population appears to be significant in the context of colorectal cancer prevention in the Indian subcontinent.

Keywords: Colorectal cancer, Case-control, Risk factors, Lifestyle, Comorbidities.

(C) 2017 The Authors. Published by Innovare Academic Sciences Pvt Ltd. This is an open access article under the CC BY license (http://creativecommons. org/licenses/by/4. 0/) DOI: http://dx.doi.org/10.22159/ajpcr.2017.v10i4.16194

\section{INTRODUCTION}

Globally, colorectal cancer is one of the major causes of morbidity and mortality leading to approximately $10 \%$ of the total cancer cases among both males and females [1,2]. The incidence of colorectal cancer has been increasing all over the world with more than 500,000 cases being diagnosed every year [1]. An increasing trend of colon and rectal cancers have been observed among men and women from the Indian subcontinent, the incidence being about 4 per 100,000 population for both sexes together and is the fifth most common cancer $(64,332$; 6.3\%) in this population [3]. The studies from China and Saudi Arabia have identified various risk factors for colorectal cancer such as age $>50$ years, male gender, illiteracy, dietary pattern, and genetic factors such as family history of colorectal and other cancers [1,4]. However, there are scant data with regard to this from this coastal region with its unique dietary pattern. This study was therefore undertaken to identify risk factors associated with colorectal cancer among the population in this region and look for any region specific influences.

\section{METHODS}

An unmatched case-control study was carried out at a tertiary care hospital attached to a medical college in Southern Karnataka. In view of its geographical situation in the coastal belt of the state, the hospital caters to a population that is largely seafaring and includes the neighboring districts and states.

Considering illiteracy as a risk factor, with an expected exposure of $12 \%$ among the controls and an anticipated odds ratio (OR) of 2.4 [4], the calculated minimum number of cases was 93 for a power of $80 \%$ and $5 \%$ level of significance. Allowing for a 1:2 allocation ratio, 100 cases and 200 controls were recruited into the study.

Cases were defined as incident cases of colorectal cancer aged $\geq 30$ years attending the surgery department of the hospital (both inpatients and outpatients) during the study period through 9 months. Controls were those individuals aged $\geq 30$ years, who were healthy, having no history of any cancer, and accompanying the patients other than the cases from the same hospital during the study period. The study protocol was approved by the Institutional Ethics Committee.

\section{Data collection}

The cases and the selected controls were approached, and a written informed consent was obtained. Using a pre-designed questionnaire, sociodemographic data such as age, gender, literacy level, and employment status were collected. Socioeconomic status was assessed using modified Udai Pareek scale [5].

Dietary habits such as consumption of fruits and vegetables and red meat were assessed. The frequency of consumption of these items was categorized into daily, alternate days, twice, or once a week and occasionally.

The level of physical activity among subjects was assessed using the International Physical Activity Questionnaire (IPAQ)-short version that queries the participants on their involvement in vigorous and moderate physical activities, walking, and other job-related physical activity, transportation-related activities, and recreational activities [6]. Each group of activities were measured separately (metabolic equivalent 
task [MET] level $\times$ minutes of activity/day $\times$ days/week) and expressed as total MET-minute/week. Further, based on the total scores, study participants were categorized into those performing low $(<600$ MET minute/week), moderate (600-3000 MET minute/week), and high (>3000 MET minute/week) level of physical activity.

Details regarding alcohol and tobacco use, family history of colorectal/any other cancers and history of other comorbidities were collected from all the cases and controls.

\section{Data analysis}

Data were analyzed using SPSS version 15.0. Univariate and multivariable logistic regressions were used to estimate the ORs and adjusted OR's with corresponding 95\% confidence interval (CI). p $<0.05$ was considered statistically significant.

\section{RESULTS}

A total of 100 cases with a confirmed diagnosis of colorectal cancer and 200 controls were recruited into the study.

Baseline characteristics of the participants and their association with colorectal cancer are shown in Table 1. In the present hospital-based study, $64 \%$ of the cases were aged $\geq 50$ years (mean age \pm standard deviation [SD]: $53.28 \pm 10.9$ years) against $41 \%$ of the controls (mean age \pm SD: $46.7 \pm 11.8$ years). $63 \%$ of the cases and $54.5 \%$ of the controls were males, and majority ( $94 \%$ ) of the study population was married. About $19.0 \%$ of the cases and $9.5 \%$ of the controls were illiterate, and nearly one-third of the study population (cases and controls) were reported to be unemployed. The majority (70\%) of the cases and controls belonged to the middle socioeconomic class. A significant association was observed between age $\geq 50$ years ( $\mathrm{OR}=2.56$; $95 \% \mathrm{CI}$ : $1.56-4.20$; $\mathrm{p}=0.001$ ) and colorectal cancer. A similar association was demonstrated between illiteracy (OR=1.83; 95\% CI: 1.05-3.18; $\mathrm{p}=0.04$ ) and having a family history of other cancers (OR=6.32; 95\% CI: $1.25-31.9 ; \mathrm{p}=0.018$ ) with colorectal cancer. However, no association was found with gender or occupation. Association of family history of colon cancer and colorectal cancer could not be determined as none of the controls reported this exposure.

Table 2 shows that $74 \%$ of the cases and $64 \%$ of the controls were consuming non-vegetarian food with $36.5 \%$ and $27.7 \%$ being frequent red meat consumers among cases and controls, respectively. Only $27 \%$ of the cases were consuming fruits compared to $63.5 \%$ of the controls. However, there was not much difference in the vegetable consumption among both the groups except for green leafy vegetables $(58.0 \%$ of cases vs. $87.6 \%$ of controls). Personal habits such as tobacco and alcohol consumption pattern were almost similar in both the groups although tobacco chewers were more among cases $(15 \%)$ compared to controls (7.0\%). Among the comorbidities, diabetes $(11.0 \%$ and $4.0 \%$ among cases and controls, respectively) and hypertension $(9.0 \%$ and $3.5 \%$ among cases and controls, respectively) were found to be more among cases as compared to control.

Table 2 depicts the strength of association between various lifestyle factors and colorectal cancer. Participants who consumed a mixed diet were at 1.6-fold risk of colorectal cancer compared to those who had only vegetarian food. The frequency of consumption of selected food items was categorized into frequent (twice a week/alternate days/daily) and less frequent (once a week/occasionally). Similarly, the risk of having colorectal cancer was 1.5 folds more among those who consumed red meat frequently, 4.7 times more among those who consumed less fruits, and 5 times higher among those who consumed green leafy vegetables less frequently. It was observed that the risk of colorectal cancer cases being associated with low physical activity was 5.8 times higher compared to controls.

On studying the association between the personal habits and the risk of colorectal cancer, it was found that the risk of having colorectal cancer was 2.3 fold higher among tobacco chewers. However, the study did not show any association between colorectal cancer and alcohol consumption. Of the comorbid conditions, diabetes showed a significant association $(\mathrm{OR}=2.97 ; 95 \% \mathrm{CI}: 1.15-7.63$; $\mathrm{p}<0.05)$ with colorectal cancer and hypertension was found to be an insignificant risk factor.

The factors showing an association with colorectal cancer at a $\mathrm{p}<0.1$ on univariate analysis were further included in the final model for multivariable regression model, and the results are shown in Table 3. Consumption of green leafy vegetables was not considered for regression model in spite of being a significant factor as this data were available only for 242 participants.

A statistically significant association of colorectal cancer was observed with factors such as age $\geq 50$ years (OR $=1.88$; 95\% CI: 1.02-3.45; $\mathrm{p}<0.05$ ), low physical activity (OR=5.66; $95 \% \mathrm{CI}: 3.10-10.34 ; \mathrm{p}<0.001)$, low frequency of consumption of fruits (OR=4.07; $95 \% \mathrm{CI}$ : 2.21-7.50; $\mathrm{p}<0.001)$, and having hypertension as a comorbidity (OR $=4.65 ; 95 \%$ CI: $1.32-16.44 ; \mathrm{p}<0.05$ )

Table 1: Baseline characteristics of the study participants

\begin{tabular}{|c|c|c|c|c|}
\hline Characteristics & Cases $n=100(\%)$ & Controls $n=200(\%)$ & Univariate OR (95\% CI) & p value \\
\hline \multicolumn{5}{|l|}{ Age (years) } \\
\hline$<50$ & $36(36.0)$ & $118(59.0)$ & 1 & \\
\hline$\geq 50$ & $64(64.0)$ & $82(41.0)$ & $2.56(1.56-4.20)$ & 0.001 \\
\hline \multicolumn{5}{|l|}{ Gender } \\
\hline Male & $63(63.0)$ & $109(54.5)$ & 1 & \\
\hline Female & $37(37.0)$ & $91(45.5)$ & $0.70(0.43-1.15)$ & 0.159 \\
\hline \multicolumn{5}{|l|}{ Education } \\
\hline Literate & $81(81.0)$ & $181(91.5)$ & 1 & \\
\hline Illiterate & $19(19.0)$ & $19(9.5)$ & $1.83(1.05-3.18)$ & 0.040 \\
\hline \multicolumn{5}{|l|}{ Occupation } \\
\hline Employed & $62(62.0)$ & $132(66.0)$ & 1 & \\
\hline Unemployed & $38(38.0)$ & $68(34.0)$ & $1.19(0.72-1.96)$ & 0.496 \\
\hline \multicolumn{5}{|c|}{ Socioeconomic status } \\
\hline Middle and high & $73(73.0)$ & $154(77.0)$ & 1 & \\
\hline Low & $27(27.0)$ & $46(23.0)$ & $1.24(0.71-2.15)$ & 0.477 \\
\hline \multicolumn{5}{|c|}{ Family H/O colon cancer } \\
\hline Absent & $95(95.0)$ & $200(100)$ & & \\
\hline Present & $5(5.0)$ & $0(0)$ & & \\
\hline \multicolumn{5}{|c|}{ Family H/O other cancers } \\
\hline Absent & $94(94.0)$ & $198(99.0)$ & 1 & \\
\hline Present & $6(6.0)$ & $2(1.0)$ & $6.32(1.25-31.90)$ & 0.018 \\
\hline
\end{tabular}

OR: Odds ratio, CI: Confidence interval 
Table 2: Association of lifestyle factors among the cases and controls

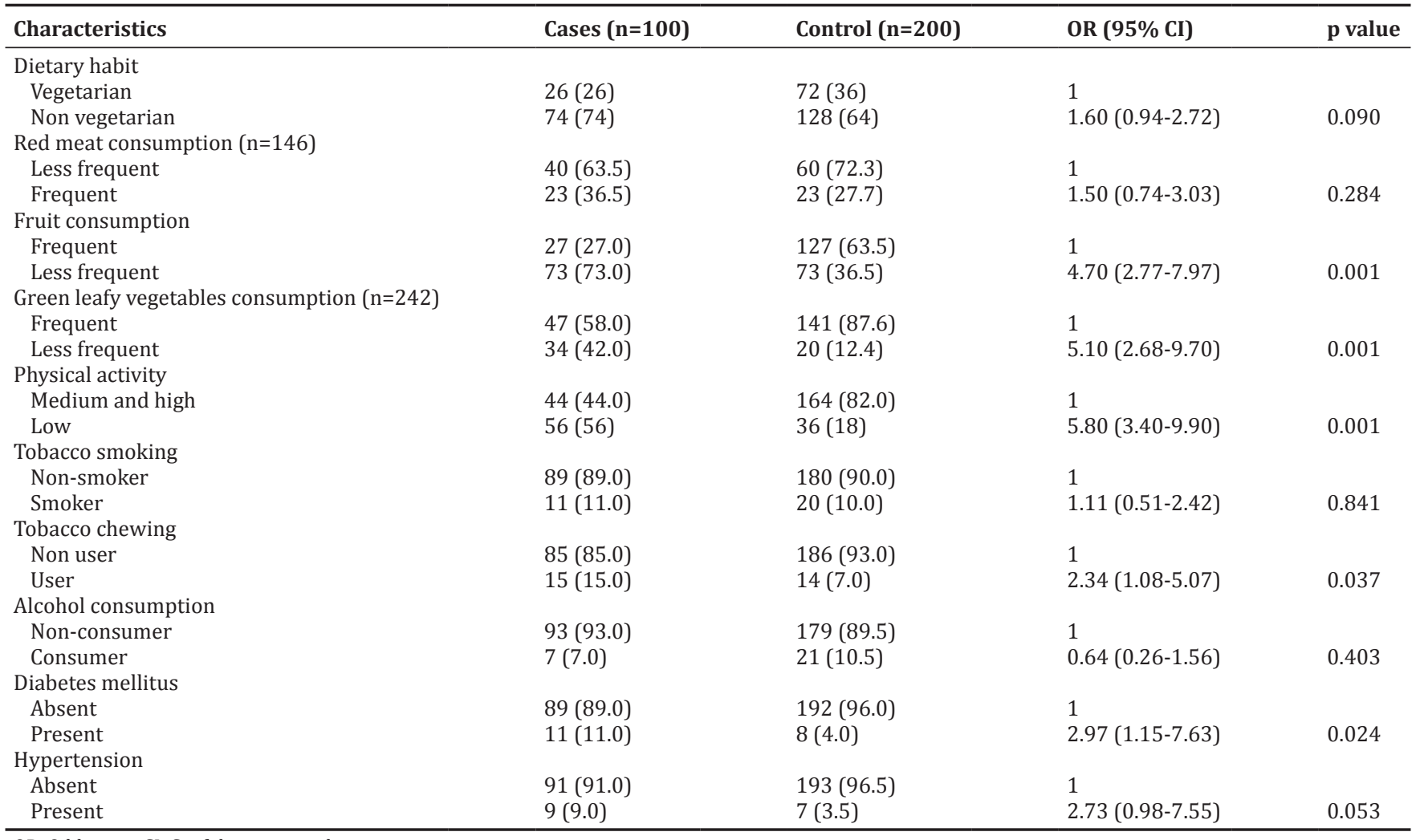

OR: Odds ratio, CI: Confidence interval

Table 3: Multivariable analysis for significant risk factors for colorectal cancer among the study population

\begin{tabular}{lll}
\hline Risk factors & Adjusted OR (95\% CI) & p value \\
\hline Age $\geq 50$ years & $1.88(1.02-3.45)$ & 0.043 \\
Being illiterate & $1.15(0.57-2.34)$ & 0.689 \\
Dietary habit & $1.50(0.80-2.82)$ & 0.205 \\
Less consumption of fruits & $4.07(2.21-7.49)$ & $<0.001$ \\
Low physical activity & $5.66(3.10-10.34)$ & $<0.001$ \\
Chewing tobacco & $1.53(0.58-4.00)$ & 0.390 \\
Having diabetes & $2.68(0.91-7.89)$ & 0.074 \\
Having hypertension & $4.65(1.32-16.44)$ & 0.017 \\
\hline
\end{tabular}

OR: Odds ratio, CI: Confidence interval

Most common complaints among the cases were blood in stools (65\%), followed by abdominal pain $(47 \%)$, fatigue $(43 \%)$, chronic diarrhea (28\%), weight loss (23\%), and loss of appetite (14\%).

\section{DISCUSSION}

In the present study, mean age $( \pm S D)$ of cases was 53.28 years ( \pm 10.99$)$ compared to controls which are similar to the finding $(54.1 \pm 11.5$ years) reported in a study from Pondicherry, India, but in contrast to the statistics reported from the USA with median age of colorectal cancer cases being 43 years. The same report revealed a male preponderance among the cases which is in conformity to the findings of our study. In the present study, among the sociodemographic characteristics, age $\geq 50$ years was significantly associated with colorectal cancer which is in agreement with the report from the USA $[7,8]$. Illiteracy was found to be a significant predictor on univariate analysis, which was similar to the findings of a study from Riyadh [4], where cases were reported to be less educated than the controls. However, a multivariable analysis incorporating the same variable did not yield any such association in the present study.
Low physical activity was found to be a significant predictor for colorectal cancer, and this observation is consistent with other studies that showed lack of physical activity to be associated with an increased risk of colorectal cancer $[9,10]$. Physical activity reduces bowel transit time thus reducing the duration of contact between fecal carcinogens and colonic mucosa [11].

Our study found that the fruit consumption was inversely associated with colorectal cancer risk which is in concordance with other studies carried out in India, Sweden, and Malaysia [12-16]. Protective effect of fruits and vegetables against colorectal cancer is attributed to the presence of certain antioxidants which prevent the DNA damage due to free radicals through various mechanisms such as removal of oxidative agents, stimulation of the immune system, regulating hormone metabolism, etc. [17]. An insignificant association was found between red meat consumption and colorectal cancer in the present study which is in agreement with the findings of previously published studies which also reported similar association between these two factors $[15,18]$.

The present study did not show an association between smoking status or alcohol consumption and colorectal cancer risk similar to the findings of earlier studies from India and Malaysia $[7,15]$. In contrast to the findings of the present study, a follow-up study from Europe did show an association between alcohol consumption and colorectal cancer [19]. However, our report shows an association between chewing tobacco and colorectal cancer on univariate analysis though not as an independent risk factor.

Existing literature reports a strong association between diabetes and colorectal cancer [20-22]. This has been explained by the elevated levels of insulin and insulin-like growth factor-1 in diabetes that leads to a proliferation of colon cells thus enhancing the risk of development of colorectal cancer [18]. Our study however failed to appreciate this association. The present study reports an association between 
hypertension and colorectal cancer while clear evidence regarding the same is not available from the existing literature.

There was a significant association between family history of other cancers and colorectal cancer which is consistent with findings obtained in other studies $[15,23]$. There have been evidence to show that family history of cancers reported by the patients is valuable in their colon cancer risk assessment [24].

The symptoms commonly reported by the cases in this study are similar to those found in another study though the frequencies are different [25]

Our study has certain limitations. As the study was set in a tertiary care hospital, the findings may not reflect the prevailing habits of the local community and therefore generalizing these findings to this region may not be appropriate. Further, the chance of recall bias is a possibility with respect to dietary intake. In this study, physical activity was considered as a surrogate variable for anthropometry. Information regarding tobacco and alcohol consumption may not be complete as these may have been underreported by the participants, and this could have affected the estimation of their association with colorectal cancer.

\section{CONCLUSION}

Creating awareness about adopting a lifestyle that incorporates adequate physical activity alongside a healthy diet inclusive of fruits and fibers could be the way forward in reducing the risk of developing colorectal cancer. Further studies could explore if individuals with the risk factors identified in this study would benefit from frequent screening.

\section{ACKNOWLEDGMENTS}

This was an Indian Council of Medical Research-Short Term Studentship study (Reference ID: 2013-00768). Authors would like to thank all the study participants.

\section{REFERENCES}

1. Chen K, Cai J, Liu XY, Ma XY, Yao KY, Zheng S. Nested case-control study on the risk factors of colorectal cancer. World J Gastroenterol 2003;9(1):99-103

2. Ferlay J, Shin HR, Bray F, Forman D, Mathers C, Parkin DM. Estimates of worldwide burden of cancer in 2008: GLOBOCAN 2008. Int J Cancer 2010;127(12):2893-917.

3. Saranath D, Khanna A. Current status of cancer burden: Global and Indian scenario. Biomed Res J 2014;1(1):1-5.

4. Almurshed KS. Colorectal cancer: Case-control study of sociodemographic, lifestyle and anthropometric parameters in Riyadh. East Mediterr Health J 2009;15(4):817-26.

5. Pareek U, Trivedi G. Manual of Socio-economic Status Scale (Rural). Delhi: Manasayan; 1980

6. International Physical Activity Questionnaire. Available from: https:// www.sites.google.com/site/theipaq/questionnaire links. [Last accessed on 2016 Jan 14]
7. Iswarya SK, Premarajan KC, Kar SS, Kumar SS, Kate V. Risk factors for the development of colorectal carcinoma: A case control study from South India. World J Gastrointest Oncol 2016;8(2):207-14.

8. Ries LA, Melbert D, Krapcho M, Mariotto A, Miller BA, Feuer EJ, et al. SEER Cancer Statistics Review, 1975-2005. Bethesda, MD: National Cancer Institute; 2008.

9. Simons CC, Hughes LA, van Engeland M, Goldbohm RA, van den Brandt PA, Weijenberg MP. Physical activity, occupational sitting time, and CRC risk in the Netherlands cohort study. Am J Epidemiol 2013;177:514-30.

10. Huxley RR, Ansary-Moghaddam A, Clifton P, Czernichow S, Parr CL, Woodward M. The impact of dietary and lifestyle risk factors on risk of colorectal cancer: A quantitative overview of the epidemiological evidence. Int J Cancer 2009;125(1):171-80.

11. Batty D, Thunee I. Does physical activity prevent cancer? Evidence suggests protection against colon cancer and probably breast cancer. BMJ 2000;128:1696-716.

12. Terry P, Giovannucci E, Michels KB, Bergkvist L, Hansen H, Holmberg L, et al. Fruit, vegetables, dietary fiber, and risk of colorectal cancer. J Natl Cancer Inst 2001;93(7):525-33.

13. Murphy N, Norat T, Ferrari P, Jenab M, Bueno-de-Mesquita B, Skeie G, et al. Dietary fibre intake and risks of cancers of the colon and rectum in the European prospective investigation into cancer and nutrition (EPIC). PLoS One 2012;7(6):e39361

14. Aune D, Chan DS, Lau R, Vieira R, Greenwood DC, Kampman E, et al. Dietary fibre, whole grains, and risk of colorectal cancer: Systematic review and dose-response meta-analysis of prospective studies. BMJ 2011;343:d6617.

15. Ramzi NH, Chahil JK, Lye SH, Munretnam K, Sahadevappa KI, Velapasamy $\mathrm{S}$, et al. Role of genetic and environment risk factors in the aetiology of colorectal cancer in Malaysia. Indian J Med Res 2014;139(6):873-82.

16. Nayak SP, Sasi MP, Sreejayan MP, Mandal S. A case-control study of roles of diet in colorectal carcinoma in a South Indian Population. Asian Pac J Cancer Prev 2009;10(4):565-8.

17. Heber D. Vegetables, fruits and phytoestrogens in the prevention of diseases. J Postgrad Med 2004;50(2):145-9.

18. Chao A, Thun MJ, Connell CJ, McCullough ML, Jacobs EJ, Flanders WD, et al. Meat consumption and risk of colorectal cancer. JAMA 2005;293(2):172-82.

19. Ferrari P, Jenab M, Norat T, Moskal A, Slimani N, Olsen A, et al. Lifetime and baseline alcohol intake and risk of colon and rectal cancers in the European prospective investigation into cancer and nutrition (EPIC). Int J Cancer 2007;121(9):2065-72

20. Larsson SC, Orsini N, Wolk A. Diabetes mellitus and risk of colorectal cancer: A meta-analysis. J Natl Cancer Inst 2005;97(2):1679-87.

21. Berster JM, Göke B. Type 2 diabetes mellitus as risk factor for colorectal cancer. Arch Physiol Biochem 2008;114(1):84-98.

22. Nerkar D, Mukherjee A, Mehta BK, Banerjee S. Metabolic syndrome associated complications. Int J Pharm Pharm Sci 2015;7:22-5.

23. Aarnio M, Mecklin JP, Aaltonen LA, Nyström-Lahti M, Järvinen HJ. Life-time risk of different cancers in hereditary non-polyposis colorectal cancer (HNPCC) syndrome. Int J Cancer 1995;64(6):430-3.

24. Murff HJ, Spigel DR, Syngal S. Does this patient have a family history of cancer? An evidence-based analysis of the accuracy of family cancer history. JAMA 2004;292(12):1480-9.

25. Hamilton W, Lancashire R, Sharp D, Peters TJ, Cheng K, Marshall T. The risk of colorectal cancer with symptoms at different ages and between the sexes: A case-control study. BMC Med 2009;7:17. 